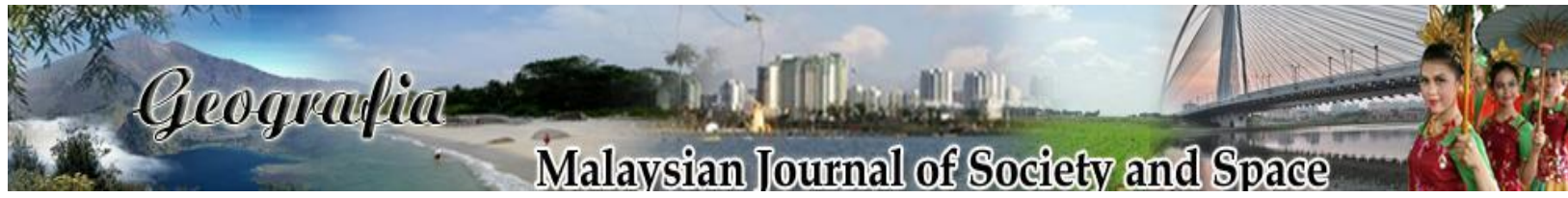

\title{
Pengaruh faktor kendiri dan institusi mempengaruhi minat mengikuti program pembelajaran sepanjang hayat PPGB-JAIS-UPSI
}

\author{
Jamal@Nordin Yunus, Khalip Musa, Mahaliza Mansor \\ Fakulti Pengurusan dan Ekonomi, \\ Universiti Pendidikan Sultan Idris
}

Correspondence: Jamal@Nordin Yunus (email: jamal@fpe.upsi.edu.my)

Received: 13 November 2019; Accepted: 04 February 2020; Published: 27 February 2020

\begin{abstract}
Abstrak
Tujuan utama program pembelajaran sepanjang hayat (PSH) untuk meningkatkan ilmu pengetahuan, nilai, kemahiran dan kompetensi. Program PSH dilaksanakan melalui inisiatif Program Pensiswazahan Guru Besar Jabatan Agama Islam Selangor (PPGB-JAIS) yang telah bermula semenjak 2009 bagi memenuhi keperluan individu dan guna tenaga. Oleh itu, keperluan ingin mengetahui apakah faktor-faktor yang menyebabkan guru-guru JAIS berminat mengikut program ini serta dikaitkan dengan falsafah dan lonjakan ketiga ke arah menghayati PSH. Tujuan utama kajian ini ialah mengenal pasti faktor kendiri dan institusi mempengaruhi minat mengikuti program ini. Kajian ini dijalankan dengan menggunakan pendekatan kuantitatif iaitu menggunakan reka bentuk deskriptif tinjauan kepada 160 orang pelajar PPGB-JAIS melalui web survey. Teknik persampelan bertujuan digunakan dalam menentukan sampel. Statistik deskriptif dan inferensi digunakan bagi menjawab tujuan kajian. Hanya 99 orang responden sahaja menjawab soal selidik tersebut. Data dianalisis menggunakan perisian SPSS dan SmartPLS bagi menentusahkan dan kebolehpercayaan faktor-faktor mempengaruhi minat mengikuti PPGB-JAIS. Hasil kajian menunjukkan faktor kendiri dan institusi menyumbang sebanyak 43 peratus mempengaruhi minat mengikuti program ini. Faktor kendiri telah menyumbang 29 peratus manakala faktor institusi menyumbang 14 peratus terhadap minat mengikut program ini. Kesimpulan kajian ini dapat membuka pandangan baharu tentang faktor kendiri dan institusi memberikan kesan terhadap minat pelajar mengikut program PSH. Hal ini menunjukkan bahawa kedua-dua faktor perlu diambil kira dalam menyediakan program PSH. Kajian mencadangkan agar pihak penyedia PSH perlu mengambil kira kedua-dua faktor ini untuk menggalakkan mereka mengikut program tersebut.
\end{abstract}

Kata kunci: pembelajaran sepanjang hayat, kendiri, institusi, minat, SmartPLS 


\title{
Self concept and institutional factors affecting students' interest to enrol in lifelong learning programmes PPGB-JAIS-UPSI
}

\begin{abstract}
The main objective of program pembelajaran sepanjang hayat (PSH) or the lifelong learning programme is to increase one's knowledge, values, skills and competencies. An example of such a programme is the headteacher certification programme which has been conducted with the cooperation of Jabatan Agama Islam Selangor (PPGB-JAIS) since 2009, and aims to fulfill the individual and human resource needs. Therefore, the need to identify the factors which motivated the JAIS teachers to enroll in the programme mentioned, and whether the factors could be related to the philosophy and third thrust towards appreciating lifelong learning. As such, the main objective of this study was to identify the self-concept factors and institutional factors which influenced the teachers to enroll in the programme. This study was conducted using the quantitative approach with a survey descriptive design. The respondents were 160 PPGB-JAIS students and they were required to answer the study via a web survey. The purposive sampling technique was utilised in order to determine the sample. Descriptive and inferential statistics were used for answering the study objectives. A total of 99 respondents answered the survey. The data was analysed using SPSS and SmartPLS for assessing the validity and reliability of the factors which influenced the students' interest in enrolling in PPGB-JAIS. The findings showed that self-concept and motivation contributed as much as 43 percent towards students' interest in enrolling in the programme. Self-concept contributed 29 percent while motivation contributed 14 percent towards students' interest in enrolling in the programme above. The study findings could help in opening new perspectives of self-concept and motivation factors in influencing students' interest to enroll in lifelong learning programmes. The results indicated that both these factors should be taken into account when preparing lifelong learning programmes. The study also suggested that the PSH preparatory team should consider these two factors to encourage students to enroll in such programmes.
\end{abstract}

Keywords: lifelong learning programmes, self-concept, institutions, interest, SmartPLS

\section{Pengenalan}

Perkembangan dan kelangsungan ekonomi sesebuah negara sedikit banyak dipengaruhi pemindahan teknologi, pembangunan bakat dan penyediaan pekerja berkemahiran (Wan \& Sirat, 2018; Sarwar-Aalam et al., 2019). Malah gabungan teknologi dan pekerja berkemahiran akan meningkatkan prestasi organisasi (Chen, 2016; Garcia-Morales et al., 2018). Hung (2007), Nirmal Kaur et al. (2018) serta Watson (2007) meramalkan pada abad ke 21 memerlukan pekerja yang berpengetahuan, bersedia berubah, belajar secara pengarahan kendiri, mengintergrasi pembelajaran dalam kehidupan, online networks dan hubungan sosial yang boleh dilaksanakan melalui pembelajaran sepanjang hayat (PSH).

Dijangkakan juga akan berlaku perubahan kualiti hidup disebabkan perubahan struktur demografi Malaysia (Farhah Hanun \& Denise Koh, 2017). Respons kepada perubahan-perubahan ini, Kanwar et al. (2019) melihat PSH merupakan salah satu cara dalam meningkatkan kemahiran pekerja dan menjana ekonomi negara. Pada peringkat awal, PSH lebih bersifat menyediakan latihan kepada pekerja dalam usaha meningkatkan kemahiran atas perubahan permintaan pasaran buruh, namun selepas 1990an PSH dilihat sebagai memenuhi tuntutan perubahan ekonomi, politik, sosial dan teknologi (Allan \& Lewis, 2009). 
Perkembangan pesat ini menyebabkan PSH penting bagi semua golongan bagi mengatasi jurang pengetahuan dan kemahiran yang tinggi pada masa depan (Collins, 2009).

Konsep dan definisi PSH adalah pelbagai dan mengikut keperluan semasa dan penyedia program seperti pihak industri, kerajaan, pembuat dasar dan juga akademik. Namun, umumnya PSH berkonsepkan pembelajaran di sepanjang hayat, pembelajaran yang boleh disesuaikan, pelbagai dan tersedia di mana-mana dan dan bila-bila masa secara berterusan (Lifelong Learning Council Queensland Inc, 2015). Menurut Tan dan Morris (2005), PSH dilaksanakan melalui kaedah secara formal (kerja kursus dan kerja berpasukan), nonformal (pembangunan profesional) dan informal (santai dan bebas).

Berdasarkan Pelan Induk Pembangunan PSH memberi definisi PSH sebagai pembelajaran yang melibatkan individu berusia 15 tahun ke atas yang memberi peluang kedua melanjutkan pengajian kepada individu bekerja bagi meningkatkan pengetahuan, kemahiran dan kompeten secara formal atau tidak formal berdasarkan pengalaman dan latihan yang diperoleh (Kementerian Pengajian Tinggi, 2011). Tujuan utama PSH ialah untuk menambahbaik pengetahuan, kemahiran dan kompeten sama ada untuk diri sendiri, sivik, sosial atau berkaitan dengan pekerjaan (Tan, 2017).

Selanjutnya pihak Kementerian Pendidikan Tinggi (KPT) melaksanakan tiga strategi utama bagi memastikan PSH sehingga tahun 2025. Tiga strategi tersebut melibatkan penjenamaan semula PSH, pembudayaan PSH dan meningkatkan kualiti program PSH. Ketiga-ketiga strategi ini dipacu dengan beberapa inisiatif bagi memastikan PSH di Malaysia berkesan dan bermanfaat. Antara inisiatif yang telah dikenal pasti ialah:

i. meningkatkan program promosi;

ii. pemantapan prasarana;

iii. penjajaran PSH dengan keperluan akreditasi; dan

iv. mengiktiraf pembelajaran terdahulu.

Kesemua strategi dan inisiatif PSH ini boleh dilaksanakan secara formal, bukan formal dan tidak formal. Program PSH berjaya sekiranya wujudnya:

i. Peningkatan kadar enrolmen PSH di IPT awam dan swasta;

ii. Peningkatan bilangan calon PSH yang memperoleh kelayakan formal; dan

iii. Peningkatan enrolmen PSH dalam program inovatif (seperti pendidikan eksekutif, pembelajaran berasaskan kerja dan pembelajaran berasaskan modul).

Di samping itu juga PSH mampu dan berupaya meningkatkan pembangunan kendiri dan profesional terhadap sikap dan nilai yang diperlukan (Tan \& Morris, 2005; Bozkurt \& Keefer, 2017). Malah bagi menghadapi pengetahuan yang baharu wujud dan kompentensi berskala tinggi, maka kemahiran asas akademik seperti literasi bahasa, matematik, sains dan penguasaan bahasa asing perlu ditekankan (World Bank, 2003; Blaschke, 2012). Pekerja yang berkemahiran dan fleksibel mampu berupaya belajar sendiri melalui PSH (Kanwar et al, 2019). Malah negara-negara di Eropah menyasarkan peningkatan 15 peratus menjelang 2020 terlibat dalam program pembelajaran sepanjang hayat (Carlsen et al., 2016).

Pihak majikan memerlukan lepasan universiti atau kolej mengetahui dan mempunyai kemahiran menyelesaikan masalah di tempat kerja (Kuhn, 1999; Harvey, 2001; Trilling \& Fadel, 2009). Ini bagi memastikan segala proses, inovasi dan perubahan sama ada di dalam atau di luar organisasi dapat ditangani dengan cepat dan berkesan (Kanwar et al., 2019). Malah berupaya menghadapi situasi kompleks dan tidak dijangkakan di masa depan. Trend bilangan pekerjaan masa kini dalam organisasi menunjukkan peningkatan pekerja yang berumur 55 hingga 64 sebanyak 53 peratus semenjak tahun 2012 (Soo \& Gusup, 2018; OECD, 2019). Berdasarkan data ini, pihak kerajaan dan organisasi perlu menyediakan program-program latihan dan peningkatan kemahiran pekerja di sepanjang kerjaya mereka. Kebanyakan organisasi telah menyediakan latihan dan bengkel bagi menyediakan pekerja berkompeten dalam menghadapi cabaran kelangsungan penghidupan masa depan (Fraile et 
al., 2018; Spante et al., 2018). Tambahan pula dalam memenuhi persaingan, penggunaan teknologi baharu, memperbaiki, perpaduan sosial, peluang kesamaan dan juga kualiti kehidupan (Carlsen et al., 2016).

Penekanan berterusan gelombang globalisasi dan pengetahuan berasaskan ekonomi telah menyebabkan bidang pendidikan juga turut terkesan (Brine, 2006). Tambahan pula persediaan ke arah IR4.00 juga menuntut para pekerja sentiasa berusaha memperbaiki dan meningkatkan diri dalam kerjaya. Justeru itu, pembelajaran sepanjang hayat merupakan respons terhadap fenomena tersebut (Broek \& Hake, 2012; Fraile et al., 2018).

Pada peringkat awal Program Pensiwazahan Guru Besar (PPGB) diperkenalkan khas untuk mensiswazahan guru besar oleh pihak Kementerian Pendidikan Malaysia (KPM). Namun program ini telah menarik minat pihak Jabatan Agama Islam Selangor (JAIS) bagi membantu guru-guru besar sekolah agama meningkatkan kelayakan akademik. Justeru itu, JAIS telah mengambil inisiatif untuk membantu guru besar dan guru-guru sekolah agama meningkatkan kelayakan akademik dengan bantuan pihak Universiti Pendidikan Sultan Idris (UPSI).

Dalam konteks PPGB-JAIS-UPSI, ia lebih merupakan pembelajaran secara formal kerana atas keperluan pemberian kelayakan akademik atau pengiktirafan. Struktur dan kurikulum pengajian digubal, dikawal dan diselaraskan mengikut keperluan pihak JAIS, UPSI dan MQA. Program ini dilaksanakan oleh pihak UPSI pada hujung minggu iaitu pada hari sabtu dan ahad, atau cuti sekolah berdasarkan keperluan pelajar-pelajar dan peraturan JAIS. Atas kejayaan perjalanan program tersebut, pihak JAIS meneruskan program ini agar guru-gurunya dapat meningkatkan kelayakan akademik dan kemahiran yang relevan dengan keperluan JAIS. Ini menunjukkan bahawa program ini memberi kesan atau impak kepada JAIS khususnya dalam meningkatkan bilangan guru-guru JAIS yang mempunyai tahap kelayakan akademik ke tahap sarjana muda.

Penyertaan guru-guru JAIS dalam program ini amat menggalakkan dan dapat ditunjukkan melalui rekod kemasukan mengikut kohort, yang mana kohort pertama menyenaraikan 56 orang peserta yang terdiri daripada guru besar dan penolong kanan sekolah agama JAIS, kohort kedua 88 orang, kohort ketiga 40 orang dan kohort keempat 43 orang. Program ini dijalankan secara eksekutif dan kelas di hujung minggu.

Lanjutan dari kejayaan program ini, pihak JAIS terus melaksanakan program ini kerana ia telah memberi kesan atau impak kepada JAIS khususnya dalam meningkatkan bilangan guru-guru JAIS mempunyai kelayakan akademik. Sehubungan dengan itu, kajian ini ingin mengetahui apakah faktor-faktor yang menyebabkan guru-guru JAIS berminat mengikut progam ini. Kajian-kajian sebelum ini kurang dibincangkan oleh penyelidikpenyelidik terdahulu seperti Ahmad (1999), Mohd Faeez et al. (2017) serta Sufean et al. (2005) berkaitan dengan faktor-faktor yang menyebabkan pelajar-pelajar (guru-guru JAIS) berminat mengikuti program ini. Justeru itu, tujuan utama kajian ini ialah mengenal pasti faktor-faktor yang mempengaruhi mereka mengikuti program ini.

\section{Kajian literature}

\section{Model PSH}

Umumnya model PSH mengutamakan pembelajaran pengarahan kendiri dan penentuan kendiri yang mengarahkan apa yang perlu dipelajari, bagaimana dipelajari dan di mana perlu dipelajari serta memahaminya dalam memenuhi keperluan profesional (Blaschke, 2012; Qalehsari et al., 2017). Model ini menekankan peningkatan kemahiran dan pengetahuan 
dengan bantuan insitusi-institusi pendidikan (Allan \& Lewis, 2009). World Bank (2003) telah membandingkan pendekatan pembelajaran tradisional dengan PSH seperti dalam Jadual 1.

Jadual 1. Perbandingan pembelajaran tradisional dan PSH

\begin{tabular}{|c|c|}
\hline Pembelajaran tradisional & Pembelajaran sepanjang hayat \\
\hline Guru sumber utama pengetahuan & Pendidik menunjuk sumber-sumber pengetahuan \\
\hline Pelajar menerima pengetahuan dari guru & Belajar melalui tingkah laku \\
\hline Belajar melalui diri sendiri & Belajar dari orang lain dan dalam kumpulan \\
\hline Ujian dijadikan pengukur tahap penguasaan kemahiran & $\begin{array}{l}\text { Pentaksiran dijadikan panduan strategi } \\
\text { pembelajaran dan masa depan }\end{array}$ \\
\hline $\begin{array}{l}\text { Guru menerima latihan secara ad-hoc semasa latihan } \\
\text { dalam perkhidmatan }\end{array}$ & $\begin{array}{l}\text { Pendidik sendiri belajar, latihan dan perkembangan } \\
\text { profesional yang berkaitan }\end{array}$ \\
\hline Semua pelajar melakukan perkara yang sama & Setiap individu merancang pembelajarannya \\
\hline Pelajar yang baik mengindinfikasikan pembelajarannya & Mengakses peluang pembelajaran sepanjang hayat \\
\hline
\end{tabular}

Sumber: World Bank, 2003

Kerajaan Malaysia bersungguh-sungguh memastikan PSH dapat dilaksanakan dengan jayanya. Setiap universiti awam diminta menggiatkan lagi program-program PSH sama ada dalam bentuk jangka pendek atau jangka panjang. Pada masa yang sama akan meningkatkan pendapatan universiti dan membantu masyarakat dalam meningkatkan kemahiran, pengetahuan dan kompetensi terkini, berfokus dan terkehadapan (Mohd Rashid, 2018). Ia juga sekaligus menyokong agenda Transformasi Nasional 2050 (TN50) dan Wawasan Kemakmuran Bersama 2030. Beberapa universiti dan institusi pendidikan awam telah menubuhkan dan menjalankan pembeajaran sepanjang hayat. Antaranya Universiti Malaya melalui Centre of Continuing Studies, Pusat Pendidikan Berterusan Unversiti Tun Hussein Onn, Pusat Khidmat Masyarakat dan Pendidikan Berterusan Universiti Islam Antarabangsa, politeknik dan kolej-kolej komuniti Malaysia.

\section{Latar teori faktor-faktor mempengaruhi minat}

Kajian ini berasaskan kepada teori pilihan Glasser (1996). Teori ini menekankan bahawa semakin baik atau tetap pemilihan sesuatu perkara itu akan menjadikan hidup seseorang lebih bermakna. Menurutnya lagi bahawa sebarang tingkah laku yang ditunjukkan berasal dari dalam dirinya (Glasser, 1997). Teori ini membantu seseorang untuk mengawal dan memimpin diri mengenal pasti tingkah laku yang berkesan bagi mencapai matlamat hidup akan datang.

Namun, segala tingkah laku ini boleh dikawal sama ada melalui tindakan (acting) atau pemikiran (thinking). Dalam konteks kajian ini pemilihan merupakan tingkah laku yang menimbulkan minat kepada sesuatu perkara yang diingini. Minat dikonsepkan sebagai kecenderungan memberi perhatian, kesukaan, tertarik dan memilih kepada sesuatu (Xihe Zhu \& Senlin Chen, 2017). Minat wujud daripada faktor dalam dan luaran diri seseorang (Schiefele, 1991). Faktor dalaman diri merujuk kepada keinginan, keseronokan atau suka kepada subjek, topik ataupun aktiviti. Malah minat merupakan elemen penting dalam proses pembelajaran (Ridzwan \& Mohamed Nor Azhari, 2016). Manakala faktor luaran diri juga 
dikenali sebagai faktor situasi yang merupakan persekitaran atau objek berkaitan dengan dirinya secara sedar ataupun tidak.

Faktor kejayaan PSH bergantung kepada nilai pembelajaran yang diperoleh, peluang pendidikan, prasarana penyedia PSH (Godinez, 2010), peranan penyedia PSH bagi menyebar, membuadayakan dan kolaboratif dengan institusi lain (Su et al., 2012). Malah pemindahan dan kepelbagaian teknologi memudahkan menyampaikan pengetahuan dalam pelbagai mod (seperti video, internet dan dan telesidang) bagi memenuhi keperluan pelajar (World Bank, 2003; Blaschke, 2012). Faktor-faktor ini juga boleh menarik minat dalam mengikuti program PSH.

Berdasarkan kajian lepas, menunjukkan terdapat dua kategori utama yang mempengaruhi minat pelajar mengikuti program PSH iaitu faktor kendiri dan faktor institusi. Faktor kendiri meliputi pengingkatan kerjaya, kelayakan akademik, dorongan keluarga dan diri sendiri (Godinez, 2010; Khasniza \& Nurul Akmar, 2017; Kanwar et al., 2019). Faktor kedua ialah faktor institusi atau penyedia PSH. Institusi dalam konteks penyedia program PSH boleh terdiri daripada universiti, kolej, sekolah, di rumah, perpustakaan, jawatankuasa atau mana-mana entiti berkait rapat dalam menyediakan program PSH (Schuller \& Watson, 2009). Setiap penyedia program PSH hendaklah mudah diakses untuk belajar, latihan dan pembangunan seperti yang diperlukan oleh peserta program.

\section{Kajian-kajian berkaitan}

Kajian Godinez (2010) mendapati wujudnya korelasi yang signifikan antara faktor individu seperti menghargai pembelajaran, akses kepada peluang pembelajaran dan ciri-ciri demografi dengan PSH. Manakala faktor-faktor penggalak luaran seperti bahasa pengantar, jarak fizikal dengan institusi dan kos pendidikan di kampus serta faktor-faktor penggalak dalaman seperti reputasi institusi dan kecenderungan pembelajaran individu turut memainkan peranan dalam mempengaruhi minat mengikuti PSH (Carlsen et al., 2016).

Dapatan kajian yang dijalankan oleh Absher dan Crawford (1996) serta Hassan et al. (2008) menyatakan bahawa prasarana pendidikan seperti bilik kuliah, makmal dan perpustakaan merupakan faktor penting dalam pemilihan kolej atau universiti oleh para pelajar. Malah sebelum itu, kajian Marjan Laal (2011) juga mendapati institusi yang menawarkan program perlu mengatasi isu peraturan yang rigid, prasarana, yuran atau kos pembiayaan, promosi, pengendali program, kesesuaian program dengan peserta dan ICT.

Manakala Arpan et al. (2003) mendedahkan bahawa faktor-faktor yang diambil kira oleh para pelajar dalam menilai imej universiti termasuklah program akademik, kehidupan sosial, prasarana pembelajaran dan persekitaran fizikal universiti yang positif secara keseluruhan atau global bagi kebanyakan orang. Faktor yang mempunyai pengaruh terbesar terhadap imej institusi pendidikan adalah kualiti profesor dan kuliah mereka (Maric et al., 2010). Kajian Ancheh et al. (2007) juga yang mendapati bahawa faktor reputasi institusi merupakan penyumbang utama dalam penentuan pemilihan institusi pendidikan di Malaysia. Manakala Osman dan Saputra (2019), mendapati imej universiti juga mempengaruhi pelajar mengikuti program pengajian khususnya berkaitan dengan kurikulum, kepuasan dan kualiti program.

Kajian berkaitan PSH dalam kalangan pendidik di Malaysia menunjukkan guru bersemangat memajukan diri dan memberi perkhidmatan terbaik, perlukan sokongan keluarga dan rakan, kemahiran penggunaan atas talian dan yakin diri (Rashid, 2015) mendapat sokongan pihak pentadbiran tetapi kurang mendapat kemudahan kewangan dan masa (Nor Kamaliah \& Ahmad Zabidi, 2018) serta bermotivasi tinggi dan berminat mengikuti program PSH (Yusop \& Abbas, 2016). Pengkaji lain seperti Hasami dan Buang (2018) turut mengakui bahawa PSH dapat meningkatkan pengetahuan dan nilai tambah diri 
pada pelajar tersebut. Tinjauan literatur menunjukkan dapatan lepas bersetuju bahawa faktorfaktor kendiri dan institusi merupakan pengaruh ke atas minat pelajar mengikuti program PSH.

\section{Kaedah kajian}

Reka bentuk kajian ini merupakan kajian deskriptif tinjauan iaitu kajian 'exploratory` serta 'explanatory` sesuatu isu yang boleh diterokai (Ary et al., 2018; McBride et al., 2018; Nardi, 2018). Kajian ini turut menentukan faktor-faktor utama mempengaruhi minat mengikut program PSH dalam kalangan guru-guru JAIS dengan mengumpul data daripada satu kumpulan populasi yang dipanggil sampel.

Soal selidik kajian ini dibina melalui bacaan tinjauan literatur, kajian-kajian terdahulu dan perbincangan ahli penyelidik dengan peneraju berkaitan dengan PSH (Jadual 2). Instrumen yang digunakan dalam kajian ini adalah borang soal selidik sebagai alat pengukur. Item-item dalam soal selidik ini merupakan soalan-soalan berbentuk tertutup. Ia menggunakan kaedah skala Likert tujuh mata poin, iaitu: (1) Sangat tidak setuju hingga (7) Sangat setuju. Perincian soal selidik mengikut taburan item seperti yang ditunjukkan dalam Jadual 2.

Jadual 2. Taburan item mengikut bahagian soal selidik

\begin{tabular}{|c|c|c|c|}
\hline Bahagian & Item Soal Selidik & Jumlah Item & Sumber Item \\
\hline A. Profil Guru & $\begin{array}{l}\text { Jantina } \\
\text { Umur } \\
\text { Kelulusan akademik } \\
\text { Kelulusan ikhtisas } \\
\text { Tempoh perkhidmatan }\end{array}$ & 5 & Penyelidik sendiri \\
\hline B. Faktor Kendiri & $\begin{array}{l}\text { Kerjaya } \\
\text { Akademik } \\
\text { Dorongan keluarga } \\
\text { Kehendak sendiri } \\
\text { Kenaikan pangkat }\end{array}$ & 5 & $\begin{array}{l}\text { Ubahsuai daripada Godinez (2010); } \\
\text { Kyndt, E., Govaerts, N., Dochy, F. et al. } \\
\text { (2011); Kanwar, Balasubramanian \& } \\
\text { Carr (2019); Tikkanen (2006); Kassim, } \\
\text { Buang \& Mohamad (2019). }\end{array}$ \\
\hline C. Faktor Institusi & $\begin{array}{l}\text { Bidang pendidikan } \\
\text { Promosi } \\
\text { Kemudahan infrastruktur } \\
\text { Pensyarah } \\
\text { Kadar yuran }\end{array}$ & 5 & $\begin{array}{l}\text { Ubahsuai daripada Carlsen, Holmberg, } \\
\text { Neghina \& Owusu-Boampong (2016); } \\
\text { Absher \& Crawford (1996); Hassan, } \\
\text { Azmi \& Mohamad (2008); Arpan, Raney } \\
\text { \& Zivnuska (2003). }\end{array}$ \\
\hline \multirow[t]{2}{*}{ D. Minat } & $\begin{array}{l}\text { Merasa suka } \\
\text { Merasa seronok } \\
\text { Sangat teruja }\end{array}$ & 3 & $\begin{array}{l}\text { Ubahsuai daripada Xihe Zhu \& Senlin } \\
\text { Chen (2017); Schiefele (1991). }\end{array}$ \\
\hline & Jumlah keseluruhan & 18 & \\
\hline
\end{tabular}

Kajian rintis dilakukan untuk menguji kesesuaian dan kefahaman item-item soal selidik. Di samping itu juga ia bertujuan untuk mengetahui reaksi responden terhadap maksud item dan jangka masa untuk dijawab (Frankel \& Wallen, 2006). Manakala Hartas (2015) berpendapat kajian rintis merupakan cara yang terbaik untuk menyelesaikan masalah sebelum kajian sebenar dijalankan sama ada penyelidikan berbentuk kuantitatif atau kualitatif. Saiz 
sampel kajian rintis tidak perlu besar tetapi memadai untuk memenuhi tujuan perbincangan awal yang berkesan tentang ujian iaitu sekitar enam hingga 10 orang (Mohd. Najib, 2003). Kajian rintis ini telah dijalankan terhadap guru-guru JAIS tahun akhir pengajian PPGB-JAISUPSI.

Penyelidik mengutip data dengan menggunakan soal selidik yang diemelkan kepada 160 orang pelajar PPGB-JAIS secara sampel bertujuan dengan menggunakan google form. Namun, sebanyak 99 orang responden (62\%) sahaja yang menjawab soal selidik tersebut. Kadar menjawab yang rendah ini adalah seiring dengan kajian-kajian yang dilakukan oleh Cook et al. (2000), Nulty (2008) serta Shannon dan Bradshaw (2002) yang menggunakan web-based survey. Pemilihan sampel bertujuan ini adalah disebabkan kebanyakan sampel tidak memberi alamat emel yang sebenar setelah kembali berkhidmat ke sekolah masingmasing. Alamat email yang diberikan adalah emel peribadi sama ada menggunakan emel yahoo, gmail atau outlook mail.

Kemudiannya, data dianalisis secara statistik untuk menggambarkan pola mengenai respons terhadap item soal selidik. Penyelidik juga menterjemahkan maksud data dengan mengaitkan keputusan ujian statistik dengan kajian-kajian lepas oleh Briggs, Coleman dan Morrison (2012) dan Morse (2016) mengenai faktor-faktor mengikut program PSH dalam kalangan guru-guru JAIS. Seterusnya data dianalisis menggunakan perisian SPSS untuk mendapatkan, kekerapan, peratusan, skor min dan sisihan piawai Manakala perisian SmartPLS digunakan untuk menentusahkan model pengukuran dan model struktural. Langkah-langkah menentusahkan model pengukuran dan model struktural dibincangkan dalam bahagian dapatan kajian.

\section{Dapatan dan perbincangan kajian}

Seramai 99 orang guru agama JAIS yang menjadi responden kajian ini dan secara keseluruhan dapatan seramai 18 orang responden (18\%) adalah lelaki dan 81 orang (82\%) adalah responden guru perempuan. Taburan ini menunjukkan bilangan responden guru perempuan lebih ramai daripada responden guru lelaki. Jadual 3 menunjukkan item-item yang mempengaruhi minat mengikuti program PSH dalam kalangan guru-guru JAIS.

Jadual 3. Faktor yang mempengaruhi minat mengikuti program PSH

\begin{tabular}{lllll}
\hline Item & Min & SP & Min Konstruk & SP Konstruk \\
\hline K1 Kerjaya & 5.65 & .812 & & \\
K2 Akademik & 5.87 & .900 & 5.77 & 0.69 \\
K3 Dorongan & 5.70 & .897 & & \\
K4 Pangkat & 5.91 & .916 & & \\
K5 Sendiri & 5.88 & .848 & & \\
& & & & \\
I1 Bidang & 4.97 & .942 & & .75 \\
I2 Promosi & 4.83 & .990 & & \\
I3 Infra & 4.89 & .925 & & \\
I4 Pensyarah & 4.99 & .875 & & \\
I5 Yuran & 4.93 & .982 & & \\
& & & & \\
M1 Suka & 5.69 & .817 & & \\
M2 Seronok & 5.60 & .903 & & \\
M3 Teruja & 5.74 & .864 & & \\
\hline
\end{tabular}


Berdasarkan Jadual 3 di atas, faktor-faktor kendiri yang mempengaruhi mengikut program PSH di UPSI menunjukkan skor min maklum balas responden berdasarkan meningkatkan kerjaya ialah 5.65 dan sisihan piawai 0.81. Skor min maklum balas responden berdasarkan meningkatkan kelayakan akademik ialah 5.87 dan sisihan piawai 0.90 dan skor min maklum balas responden tentang dorongan keluarga dan pihak sekolah ialah 5.70 dan sisihan piawai 0.89. Manakala skor min item atas sebab keperluan kenaikan pangkat ialah 5.91 dan sisihan piawai 0.91 dan akhir sekali skor min atas dorongan diri sendiri ialah 5.88 dan sisihan piawai 0.84 . Min tertinggi dalam faktor kendiri ialah atas keperluan naik pangkat dan yang terendah ialah item untuk kerjaya. Skor min keseluruhan untuk faktor kendiri ialah 5.77 dan sisihan piawai 0.69 .

Item-item yang berkaitan dengan faktor institusi pula menunjukkan skor min maklum balas responden terhadap UPSI sebagai jenama institusi pendidikan ialah 4.97 dan sisihan piawai 0.94. Seterusnya, diikuti dengan promosi skor min 4.83, infrasruktur di UPSI dengan skor min 4.89, kualiti pensyarah ialah 4.99, yuran pengajian skor min 4.93. Item yang paling tinggi skor min ialah kualiti pensyarah dan skor min paling rendah ialah item promosi. Secara keseluruhan skor min faktor institusi ialah 4.92 dan sisihan piawai 0.75.

Bagi pemboleh ubah minat, terdapat tiga item yang telah digunakan bagi mengukur minat pelajar terhadap program PSH. Skor min paling tinggi ialah item keterujaan pelajar iaitu 5.7, diikuti item suka iaitu 5.69 dan akhir sekali item keseronokan iaitu 5.60. Secara keseluruhan skor min bagi minat ini ialah 5.67 dan sisihan piawai 0.77.

Analisis Partial Least Square (PLS-SEM) dilaksanakan dalam kajian ini bagi membentuk model regresi dan menentukan sama ada model yang dibangunkan sepadan atau stabil dengan data yang dikutip seperti yang ditunjukkan dalam Rajah 1. Analisis PLS ini membolehkan penilaian terhadap kesahan dan kebolehpercayaan model pengukuran dan menganggarkan pengaruh antara pemboleh ubah-pemboleh ubah laten dalam kajian (model struktur). Rajah 1 menunjukkan terdapat tiga pemboleh ubah laten atau konstruk iaitu pemboleh ubah faktor kendiri, faktor institusi dan minat.

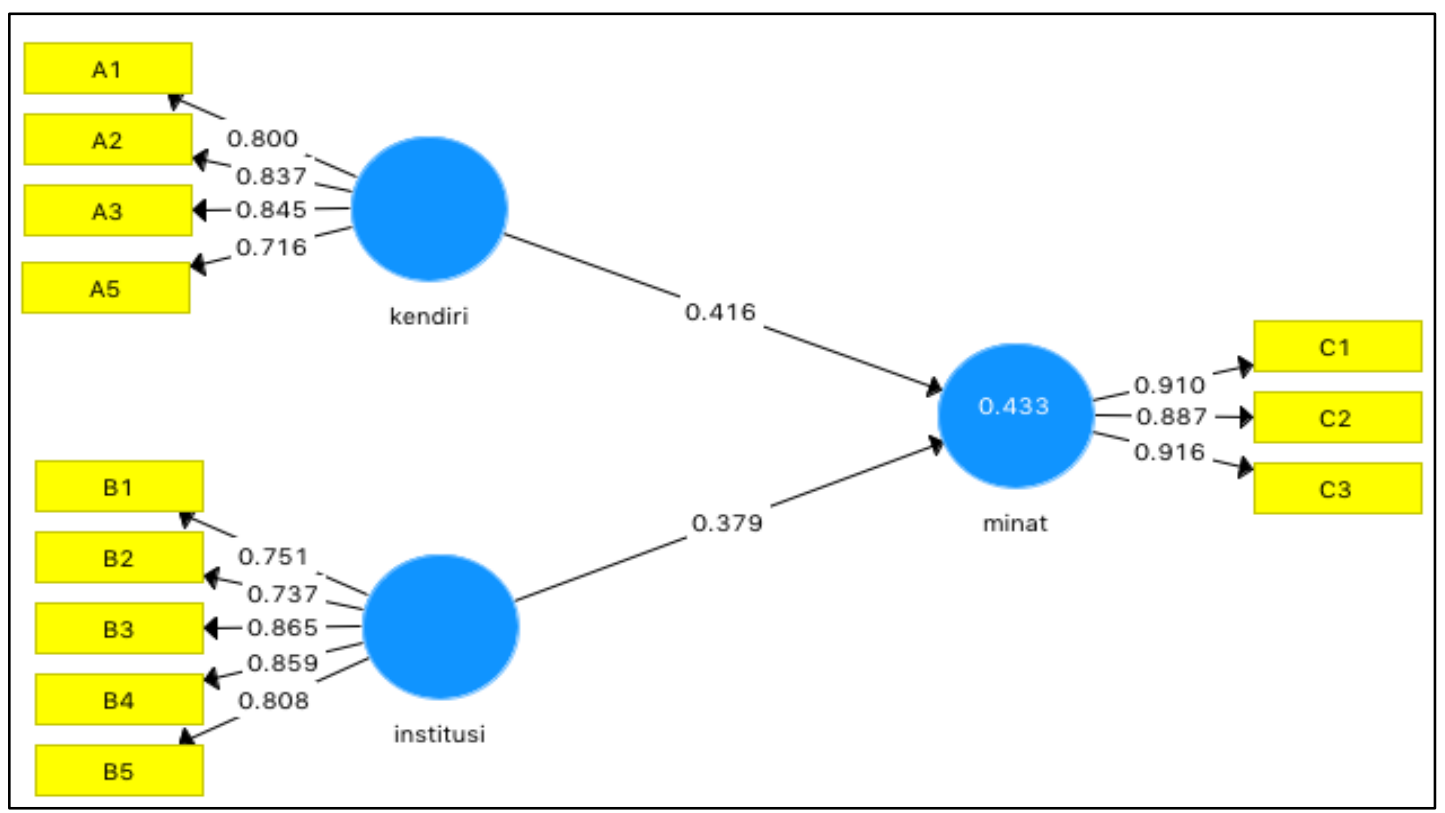

Rajah 1. Model Konseptual dan Algorithm PLS 


\section{Model pengukuran}

Bagi memastikan model pengukuran (model luaran) memenuhi syarat kebolehpercayaan dan kesahan pemboleh ubah, terdapat empat ciri utama perlu dipenuhi iaitu faktor muatan setiap indikator, komposit kebolehpercayaan, kesahan konvergen dan kesahan diskriminan serta silang muatan faktor. Pada peringkat awal, pengujian model dimulai dengan melihat nilai faktor muatan bagi setiap indikator. Nilai yang boleh diterima bagi sebuah model adalah 0.7 dan ke atas (Hair et al., 2017). Didapati indikator A4 mempunyai nilai faktor muatan kurang daripada 0.7. Sehubungan dengan itu, indikator tersebut digugurkan bagi memastikan semua indikator mempunyai nilai melebihi 0.7. Jadual 4 menunjukkan faktor muatan bagi setiap indikator selepas indikator A4 digugurkan. Hasil analisis dari Jadual 4, didapati semua indikator mempunyai nilai faktor muatan melebihi 0.7 .

Jadual 4. Silang muatan faktor

\begin{tabular}{llll}
\hline Item & Institusi & Kendiri & Minat \\
\hline A1 & 0.359 & $\mathbf{0 . 8 0 0}$ & 0.468 \\
A2 & 0.238 & $\mathbf{0 . 8 3 7}$ & 0.468 \\
A3 & 0.284 & $\mathbf{0 . 8 4 5}$ & 0.488 \\
A5 & 0.307 & $\mathbf{0 . 7 1 6}$ & 0.332 \\
B1 & $\mathbf{0 . 7 5 1}$ & 0.314 & 0.399 \\
B2 & $\mathbf{0 . 7 3 7}$ & 0.177 & 0.281 \\
B3 & $\mathbf{0 . 8 6 5}$ & 0.404 & 0.485 \\
B4 & $\mathbf{0 . 8 5 9}$ & 0.299 & 0.485 \\
B5 & $\mathbf{0 . 8 0 8}$ & 0.243 & 0.439 \\
C1 & 0.507 & 0.524 & $\mathbf{0 . 9 1 0}$ \\
C2 & 0.512 & 0.424 & $\mathbf{0 . 8 8 7}$ \\
C3 & 0.426 & 0.555 & $\mathbf{0 . 9 1 6}$ \\
\hline
\end{tabular}

Analisis seterusnya menentukan kebolehpercayaan indikator. Nilai kebolehpercayaan dalaman dan komposit yang diukur menggunakan kaedah Alpha Cronbach berada pada 0.7 dan ke atas (Hair et al., 2017). Dalam Jadual 5 menunjukkan nilai keboelehpercayaan dalaman semua pemboleh ubah laten adalah melebih 0.7. Begitu juga nilai komposit melebihi 0.7 . Ini bermakna semua pemboleh ubah laten mempunyai kebolehpercayaan yang tinggi.

Jadual 5. Komposit kebolehpercayaan

\begin{tabular}{llll}
$\begin{array}{l}\text { Konstruk } \\
\text { Reflektif }\end{array}$ & Alpha Cronbach & $\begin{array}{l}\text { Komposit } \\
\text { Kebolehpercayaan }\end{array}$ & AVE \\
\hline Kendiri & 0.814 & 0.877 & 0.642 \\
Minat & 0.889 & 0.931 & 0.818 \\
Institusi & 0.865 & 0.902 & 0.649 \\
\hline
\end{tabular}

Analisis kesahan konvergen pula diukur melalui kaedah Average Variance Extract (AVE) yang mempunyai nilai $0.5 \mathrm{ke}$ atas bagi setiap pemboleh ubah yang digunakan. Jadual 5 menunjukkan semua pemboleh ubah kajian mempunyai nilai AVE melebihi 0.5. Ini menjelaskan bahawa semua pemboleh ubah laten mempunyai kesahan konvergen. Manakala kesahan diskriminan ditentukan melalui dua kaedah iaitu kriteria Fornell-Larcker (1981) dan silang faktor muatan. Analisis kriteria Fornell-Larcker dilakukan dengan punca kuasa dua AVE $(\sqrt{A V E})$. Dari Jadual 6 didapati nilai 0.806 bagi pemboleh ubah institusi, nilai 0.801 bagi pemboleh ubah kendiri dan nilai 0.905 bagi pemboleh ubah minat. Nilai kriteria FornellLarcker mestilah melebihi daripada nilai korelasi antara pemboleh ubah laten. Jadual 6 
menunjukkan semua kriteria Fornell-Larcker telah dipenuhi. Kaedah kedua melalui melihat kepada silang faktor muatan. Setiap faktor muatan (luar) perlu lebih besar berbanding dengan nilai dalam kumpulannya. Ini dapat ditunjukkan dalam Jadual 4 di atas.

Jadual 6. Kriteria Fornell-Larcker

\begin{tabular}{llll}
\hline Konstruk & Institusi & Kendiri & Minat \\
\hline Institusi & $\mathbf{0 . 8 0 6}$ & & \\
Kendiri & 0.367 & $\mathbf{0 . 8 0 1}$ & \\
Minat & 0.532 & 0.555 & $\mathbf{0 . 9 0 5}$ \\
\hline
\end{tabular}

Keseluruhannya model pengukuran ini telah memenuhi syarat menentusahkan model berdasarkan kriteria kesahan dan kebolehpercayaan indikator dan pemboleh ubah laten. Langkah ini penting sebelum menguji model struktur dalam kajian ini.

\section{Model struktur}

Bagi mengukur model struktur, Hair et al. (2017) mencadangkan dua komponen utama sebagai kriteria utama mengukur model struktur iaitu $R^{2}$ dan pekali laluan (path coefficients) digunakan. Nilai $R^{2}$ digunakan untuk melihat aras kekuatan pangaruh pemboleh ubah eksogen (kendiri dan institusi) terhadap pemboleh ubah endogen (minat). Hasil daripada analisis mendapati nilai $R^{2}=0.433$. Ini jelaskan bahawa perubahan yang berlaku sebanyak 43.3 peratus terhadap minat adalah disebabkan faktor kendiri dan institusi. Justeru itu, pemboleh ubah kendiri dan institusi mempunyai pengaruh terhadap minat mengikuti program PSH.

Bagi menguji pekali laluan, menunjukkan terdapat hubungan yang positif dan signifikan antara faktor kendiri dengan minat $(\beta=0.416, \mathrm{t}=5.586)$. Begitu juga faktor institusi mempunyai hubungan positif dan signifikan dengan minat $(\beta=0.379, \mathrm{t}=5.5279)$ seperti dalam Rajah 1 dan Rajah 2. Secara keseluruhannya, dapatan kajian ini mengesahkan bahawa faktor kendiri dan faktor institusi merupakan faktor terpenting dalam mempengaruhi minat mengikuti program PSH.

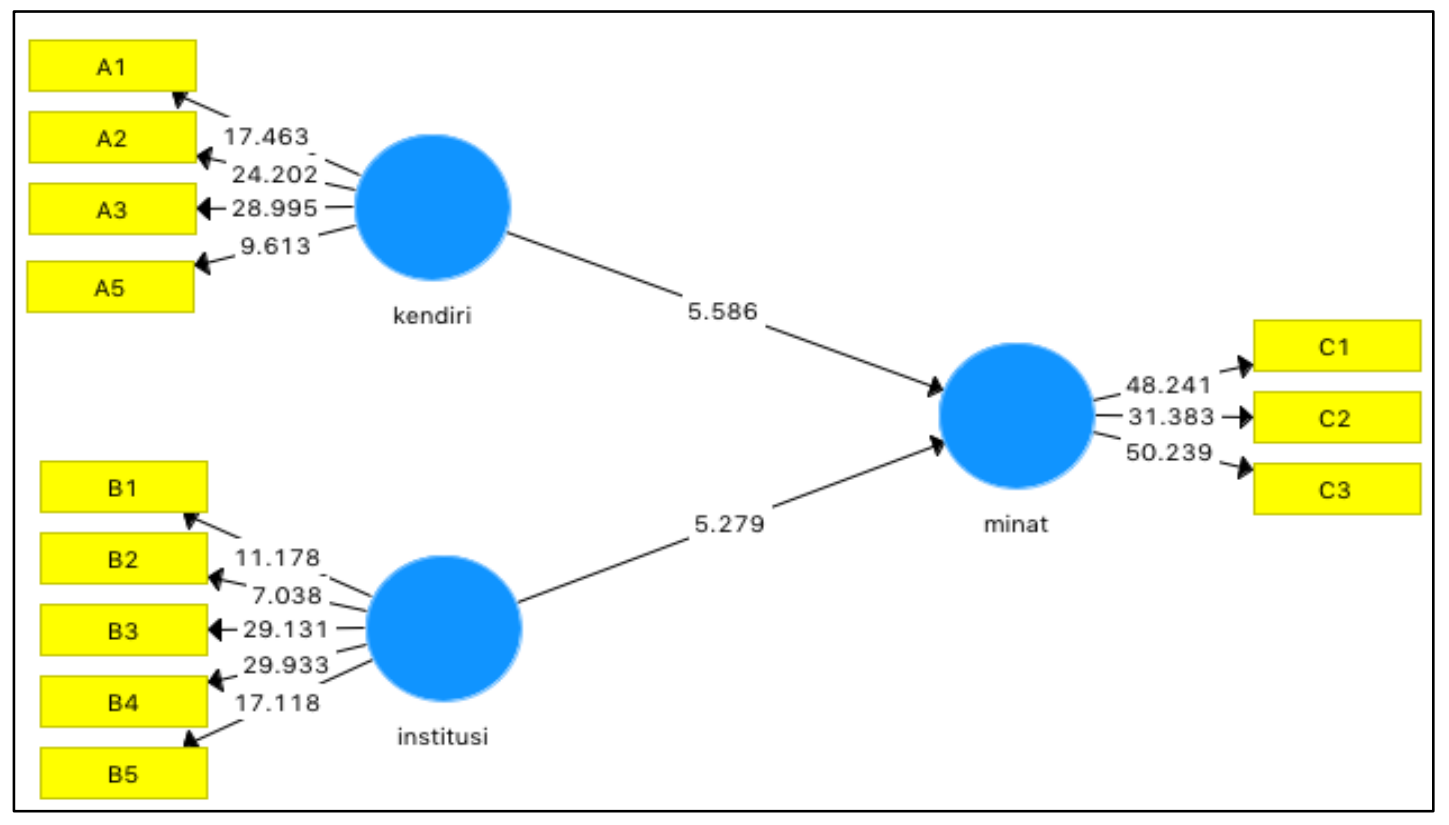

Rajah 2. Model struktural 
Kajian ini mendapati faktor kendiri dan institusi mempunyai pengaruh dengan minat mengikuti program PSH. Faktor kendiri mempunyai hubungan yang positif dengan minat. Dapatan kajian ini selari dengan kajian oleh Godinez (2010) serta Kanwar et al. (2019). Begitu juga hubungan positif antara institusi dengan minat, dapatan kajian ini selari dengan kajian-kajian oleh Ancheh et al. (2007); Osman dan Saputra (2019); serta Su et al. (2012).

Manakala kajian Hasami dan Buang (2018) turut mengakui bahawa program PSH dapat meningkatkan pengetahuan peserta. Ini selaras dengan dapatan kajian ini yang menunjukkan keperluan akademik guru-guru JAIS merupakan faktor pendorong bagi mengikut program ini. Selanjutnya faktor diri peserta berperanan mempengaruhi minat mengikuti program PSH. Kajian ini seiring dengan saranan Mohd Faeez et al. (2017) yang menekankan bahawa kualiti perkhidmatan awam bergantung kepada kualiti penjawat awam. Bagi meningkatkan kualiti perkhidmatan, kerajaan perlu melatih tenaga pekerja bagi meningkatkan kemahiran, pengetahuan dan berinovasi.

Faktor institusi juga berperanan mempengaruhi minta mengikut program PSH. Kajian ini menunjukkan faktor institusi seperti kemudahan prasarana, tenaga pengajar, yuran, promosi dan bidang keperluan merupakan penarik minat kepada program PSH. Menurut Khasniza dan Nurul Akmar (2017) serta Kanwar et al. (2019) bahawa faktor-faktor tersebut perlu diambilkira dalam menawarkan program PSH. Ini disebabkan pelajar biasanya akan memilih institusi pendidikan berdasarkan kekuatan atau kelebihannya berbanding dengan institusi yang lain.

Namun dalam kajian ini, promosi menawarkan program PSH menunjukkan skor min rendah. Ia menggambarkan mungkin disebabkan promosi program ini dilakukan oleh pihak JAIS sendiri. Pihak UPSI hanya memberi taklimat kepada guru-guru yang berminat setelah pihak JAIS mengedarkan pekeliling jemputan menghadiri taklimat PPGB-JAIS-UPSI. Walau bagaimanapun, kajian dan cadangan Absher dan Crawford (1996) Arpan et al. (2003) serta Hassan et al. (2008) menyatakan promosi dari pihak penyedia program PSH juga berperanan dalam mempengaruhi minat pelajar.

Implikasi kajian ini menunjukkan pentingnya setiap individu mempunyai kecenderungan minat mengikuti program PSH bagi memenuhi keperluan diri, ekonomi dan kerjayanya. Carlsen et al. (2016) menegaskan bahawa dasar di negara Eropah menyarankan agar setiap institusi pengajian tingginya meningkatkan bilangan pelajar mengikut program PSH bagi menghadapi sebarang perubahan ekonomi dan globalisasi. Malah PSH merupakan salah satu faktor menghadapi keperluan perubahan pekerjaan dalam organisasi.

Untuk menjadi benar-benar berkesan, PSH mesti memasukkan perspektif global dan dinamik peristiwa dunia yang memberi kesan kepada keberkesanan pembangunan kendiri di samping dapat meningkatkan kerjaya dan kenaikan pangkat. Benarlah bahawa inisiatif PSH secara sistematik biasanya akan membawa kepada peningkatan keupayaan kepimpinan dan meningkatkan prestasi organisasi (Amagoh, 2009). Program PSH adalah satu proses yang berterusan yang tidak harus terhad kepada latihan kepimpinan, arahan rasmi kepada kemahiran profesional, prestasi dalam fungsi kerja pembangunan, dan penyertaan dalam program-program pembangunan diri. Namun, perlu diteruskan di peringkat penyedia program yang dapat memenuhi keperluan dan kehendak pelanggan. Pengkaji berharap agar dapatan kajian ini nanti dapat memberikan sumbangan dan dimanfaatkan oleh penggubal dan pelaksana polisi serta pemimpin pada semua peringkat dalam merancang program yang bersesuaian dan memastikan keberkesanan serta kemajuan yang konkrit program PSH diminati dan dianjurkan mengikut keperluan pelanggan.

Walau bagaimanapun, hasil penyelidikan ini tidak boleh digenaralisasikan kepada populasi yang setara kerana ia dilaksanakan menggunakan kaedah web non-probability surveys. Couper (2000) menjelaskan penggunaan web biasanya tidak memungkinkan untuk 
mendapat jumlah responden yang diperlukan. Antara sebabnya soal selidik melalui web tidak menentukan jangka masa menjawab, membuka emel atau lupa membuka emel.

\section{Kesimpulan}

Kajian ini telah menguji faktor kendiri dan institusi terhadap minat mengikuti PSH. Analisis SmartPLS telah mengesahkan bahawa kedua-dua faktor tersebut telah menyumbang sebanyak 43 peratus terhadap minat. Hasil kajian ini juga telah menyokong dan memperkayakan kajian literatur yang lepas. Berdasarkan dapatan kajian ini, diharapkan kerjasama pihak universiti dan agensi luar dapat diteruskan dalam merealisasikan pelaksanaan PSH sebagai salah satu program peningkatan pengetahuan, kemahiran, nilai tambah dan kesedaran kendiri. Pengkaji mencadangkan agar hasil kajian ini dijadikan asas kepada kajian-kajian selanjutnya bagi melihat keberkesanan program PSH yang dilaksanakan secara usahasama di antara dua agensi berbeza.

\section{Penghargaan}

Penyelidikan ini telah dibiayai oleh Universiti Pendidikan Sultan Idris (UPSI) melalui Geran Penyelidikan Universiti (2018-0026-107-01).

\section{Rujukan}

Absher, K., \& Crawford, G. (1996). Marketing the community college starts with understanding students' perspectives. Community College Review, 23(4), 59-67.

Ahmad Rosli. (1999). Keperluan latihan di kalangan guru bukan siswazah Jabatan Agama Islam Selangor (JAIS). [Project Paper Report] Retrieved from http://psasir.upm.edu.my/id/eprint/9157/1/FPP_1999_48_A.pdf .

Allan, B., \& Lewis, D. (2009). Time, individual learning careers, and lifelong learning. In Researching transitions in lifelong learning (pp. 50-59). Routledge.

Amagoh, F. (2009). Leadership development and leadership effectiveness. Management Decision, 47(6), 989- 999.

Ancheh, K. S. B., Krishnan, A., \& Nurtjahja, O. (2007). Evaluative criteria for selection of private universities and colleges in Malaysia. Journal of International Management Studies, 2(1), 1-11.

Arpan, L., Raney, A., \& Zivnuska, S. (2003). A cognitive approach to understanding university image, Corporate Communications: An International Journal, 8(2), 97-113.

Ary, D., Jacobs, L. C., Irvine, C. K. S., \& Walker, D. (2018). Introduction to research in education. United States: Cengage Learning.

Blaschke, L. M. (2012). Heutagogy and lifelong learning: A review of heutagogical practice and self-determined learning. The International Review of Research in Open and Distributed Learning, 13(1), 56-71.

Bozkurt, A., \& Keefer, J. (2017). Participatory learning culture and community formation in connectivist MOOCs. Interactive Learning Environments, 26(6), 776-788.

Briggs, A. R. J., Coleman, M., \& Morrison, M. (2012). Introduction. In Briggs, A. R. J., Coleman, M., \& Morrison, M. (Eds.), Research methods in educational leadership and management (pp. 1-12). London, England: Sage. 
Brine, J. (2006). Lifelong learning and the knowledge economy: Those that know and those that do not the discourse of the European Union. British Educational Research Journal, $32,649-665$.

Broek, S., \& Hake, B.J. (2012). Increasing participation of adults in higher education: Factors for successful policies. International Journal of Lifelong Education, 31, 397-417.

Carlsen, A., Holmberg, C., Neghina, C., \& Owusu-Boampong, A. (2016). Closing the gap: Opportunities for distance education to benefit adult learners in higher education. Hamburg, Germany: UNESCO Institute for Lifelong Learning.

Chen, I. (2016). Work engagement and its antecedents and consequences: A case of lecturers teaching synchronous distance education courses. Computers in Human Behavior, 72, 655-663.

Collins, J. (2009). Lifelong Learning in the 21st Century and Beyond. Journal of RadioGraphics, 29(2), 613-622.

Cook, C., Heath, F., \& Thomson, R. (2000). A meta-analysis of response rates in Web- or Internetbased surveys. Educational \& Psychological Measurement, 60(6), 821-826.

Couper, M.P. (2000). Web surveys: A review of issues and approaches. Public Opinion Quarterly, 64(4), 464-494.

Farhah Hanun Ngah, \& Denise Koh Choon Lian (2017). Kualiti hidup dan aktiviti fizikal warga emas. Geografia: Malaysian Journal of Society and Space, 13(2), 44-53.

Fornell, C. \& Larcker, D.F. (1981). Evaluating structural equation models with unobservable variables and measurement error. Journal of Marketing Research, 18(1), 39-50.

Fraile, M.N., Peñalva-Vélez, A., \& Lacambra, A.M.M. (2018). Development of digital competence in secondary education teachers' training. Education Sciences, 8(3), 1-12.

Frankel, J. R., \& Wallen, N. E. (2006). How to design and evaluate research in education. New York: McGraw-Hill.

Garcia-Morales, V. J., Martín-Rojas, R., \& Lardón-López, M. E. (2018). Influence of social media technologies on organizational performance through knowledge and innovation. Baltic Journal of Management, 13(3), 345-367.

Glasser, W. (1996). Choice theory. New York: Harper-Collins.

Glasser, W. (1997). A new look at school failure and school success. Phi Delta Kappan, 78, 596-602.

Godinez, E.U. (2010). A correlation study of the factors that influence lifelong learning in army civilian corps. Dissertaion, University of Phoenix.

Hair, J.F., Hult, G.T.M., Ringle, C.M., \& Sarstedt, M. (2017). A primer on Partial Least Squares Structural Equation Modeling (PLS-SEM). Thousand Oaks, CA: Sage.

Hartas, D. (ed.). (2015). Educational research and inquiry: Qualitative and quantitative approaches. London: Bloomsbury Publishing.

Harvey, L. (2001). Defining and measuring employability. Quality in Higher Education, 7(2), 97-109.

Hasami, H., \& Buang, N.A. (2018). Keberkesanan program pembelajaran sepanjang hayat (PSH) terhadap pengetahuan dan tahap kemahiran pelajar kolej komuniti. Jurnal Pendidikan Malaysia, 43(3), 89-106.

Hassan, M.A., Azmi, M.Z., \& Mohamad, M.S. (2008). Factors influencing students' choice of higher institutions of learning. Paper presented at the Educational Research Seminar for Students. 120-126.

Hung, N.T. (2007). Understanding lifelong learning: A perspective on the world today and Vietnam. Korean Journal of Educational Policy, 4(2), 9-16.

Kanwar, A., Balasubramanian, K., \& Carr, A. (2019). Changing the TVET paradigm: New models for lifelong learning. International Journal of Training Research, 17, 54-68. 
Kassim, Z., Buang, N. A., \& Mohamad, N. (2019). Understanding the perception of lifelong learning programmes requirements towards employee's career development. International Journal of Recent Technology and Engineering, 8(2 Special Issue 9), 432-437. https://doi.org/10.35940/ijrte.B1097.0982S919

Kementerian Pengajian Tinggi. (2011). Blueprint on enculturation of lifelong learning for Malaysia. Putrajaya: Bahagian Perancangan dan Penyelidikan. Retrieved from https://drive.google.com/file/d/0B9ZPR6HxY7PXTnNjaDBRd1d1cEE/view

Khasniza Abd Karim, \& Nurul Akmar Kamaruddin. (2017). Lifelong learning impact in transforming human capital: Case study at Polytechnic Sultan Salahuddin Abdul Aziz Shah. Proceeding 7th. Conference of Education-Technical, Vocational Education and Training. Kota Bharu, Kelantan.

Kuhn, D. (1999). A developmental model of critical thinking. Educational Researcher, 28(2), $16-46$.

Kyndt, E., Govaerts, N., Dochy, F., \& Baert, H. (2011). The learning intention of lowqualified employees: A key for participation in lifelong learning and continuous training. Vocations and Learning, 4(3), 211-229.

Lifelong Learning Council Queensland Inc. (2015). What is lifelong learning? Retrieved November 23, 2015, from http://www.llcq.org.au/01_cms/details.asp?ID=12

Marič, M., Pavlin, J., \& Ferjan, M. (2010). Educational institution's image: A case study. Organizacija, 43(2), 58-65.

Marjan Laal. (2011). Barriers to lifelong learning. Procedia - Social and Behavioral Sciences, 28, 612-615,

Maslin-Prothero, S. E. (1997) A perspective on lifelong learning and its implications for nurses. Nurse Education Today 17(6), 431-436

McBride, K.A., MacMillan, F., George, E.S., \& Steiner, G.Z. (2018). The use of mixed methods in research. In P. Liamputtong (Ed.), Handbook of research methods in health social sciences (pp. 1-19). Singapore: Springer.

Mohd Faeez Ilias, Zetty Nurzuliana Rashed, Ahmad Shafiq Mat Razali, \& Muhammad Syakir Sulaiman. (2017). Pemerkasaan latihan keguruan ke arah pembudayaan pengajaran dan pembelajaran Pendidikan Islam sepanjang hayat. Dlm. Prosiding Seminar Pendidikan Islam Sepanjang Hayat 2017 (PISH2017), Putrajaya (pp 38-44).

Mohd Rashid Ab Hamid. (2018). PSH tingkat daya saing industri, Berita Harian, 19 Februari. Retrieved from https://www.pressreader.com/malaysia/beritaharian5831/ 20180219/281638190679490

Mohd Yusop, M., \& Abbas, L.N. (2016). Kesediaan guru teknikal melanjutkan pengajian ke peringkat tinggi. Online Journal for TVET Practioners, 1(1). Retrieved from https://publisher.uthm.edu.my/ojs/index.php/oj-tp/article/view/4759

Mohd. Najib Abdul Ghaffar. (2003). Reka bentuk tinjauan soal selidik pendidikan. Sekudai: Penerbit Universiti Teknologi Malaysia.

Morse, J. M. (2016). Mixed method design: Principles and procedures. London: Routledge.

Nardi, P.M. (2018). Doing survey research: A guide to quantitative methods. London: Routledge.

Nirmal Kaur Hari Singh, Lai Wei Sieng, \& Mohd Nasir Mohd Saukani. (2018). Impact of education levels on economic growth in Malaysia: A gender base analysis. Geografia: Malaysian Journal of Society and Space, 14 (4), 13-26.

Nor Kamaliah, \& Ahmad Zabidi. (2018). Kepimpinan sekolah dan pembelajaran sepanjang hayat dalam kalangan guru di Dungun, Terengganu. JuPiDi: Jurnal Kepimpinan Pendidikan, 5(2), 45-63.

Nulty, D. D. (2008). The adequacy of response rates to online and paper surveys: What can be done?. Assessment \& Evaluation in Higher Education, 33(3), 301-314. 
OECD. (2019). Envisaging the future of education and jobs. Trends, data, and drawings. Accessed 13 March 2019. Retrieved from http://www.oecd.org/education/Envisioningthe-future-of-education-and-jobs.pdf

Osman, A., \& Saputra, R. (2019). A pragmatic model of student satisfaction: A viewpoint of private higher education, Quality Assurance in Education, 27(2), 142-165.

Qalehsari, M.Q., Khaghanizadeh, M., \& Ebadi, A. (2017). Lifelong learning strategies in nursing: A systematic review. Electronic Physician, 9(10), 5541-5550. https://doi:10.19082/5541

Rashid, R. A. A. (2015). Pendidikan sepanjang hayat dan cabaran sosial pada kalangan pelajar dewasa. Asean Journal of Teaching and Learning in Higher Education (AJTLHE), 7(1), 26-32.

Ridzwan Che' Rus \& Mohamed Nor Azhari Azman. (2016). Pengaruh minat terhadap pembentukan pekerja berkemahiran di Malaysia: Kajian kes pelatih Institut Latihan Perindustrian Kuala Lumpur (ILPKL). Geografia: Malaysian Journal of Society and Space, 12(3), 168-180.

Sarwar-Aalam, M. D., Wang, D., \& Rafique, K. (2019). Chinese one belt-one road scholarship initiative and its impact on sustainable development of the education industry. Paper presented at the ACM International Conference Proceeding Series, 263267.

Schiefele, U. (1991). Interest, learning, and motivation. Educational Psychologist, 26, 299323.

Schuller, T., \& Watson, D. (2009). Learning through life: Inquiry into the future for lifelong learning. NIACE: Leicester.

Shannon, D.M., \& Bradshaw, C.C. (2002). A comparison of response rate, response time, and costs of mail and electronic surveys. The Journal of Experimental Education, 70(2), 179-192.

Soo Eun Chae, \& Gusup Kang. (2018). Determinants of older Korean adults' participation in life-long learning programmes and life satisfaction. International Journal of Lifelong Education, 37(6), 689-700. https://doi: 10.1080/02601370.2018.1528306

Spante, M., Sofkova, S., Hashemi, M. L., Lundin, M., \& Algers, A. (2018). Digital competence and digital literacy in higher education research: Systematic review of concept use. Cogent Education, 5, 1-21.

Su, Y.H., Feng, L.Y., Yang, C.C., \& Chen, T.L. (2012). How teachers support university students' lifelong learning development for sustainable futures: The student's perspective. Futures, 44, 158-165.

Sufean Hussin, Shahril Marzuki, Ahmad Zabidi Abdul Razak, Habib Md.Som, \& Alina Ranee (ed.) (2005). Pentadbiran dalam pembangunan pendidikan. Bentong: PTS Publications.

Tan, C. (2017). Lifelong learning through the skills future movement in Singapore: Challenges and prospects. International Journal of Lifelong Education, 36(3), 278-291.

Tan, C., \& Morris, J. (2005). Undergraduate college students, laptop computers, and lifelong learning. The Journal of General Education, 54(4), 316-338.

Tikkanen, T. (2006). The lifelong learning debate and older workers. In T. Tikkanen, \& B. Nyhan (Eds.), Promoting lifelong learning for older workers: An international overview (pp. 18-47). Luxembourg City, Luxembourge: Cedefop Reference Series.

Trilling, B., \& Fadel, C. (2009). 21st century skills: Learning for life in our times. San Francisco: Wiley.

Wan, C., \& Sirat, M. (2018). The development of Malaysian higher education. Asian Education and Development Studies, 7(2), 144-156.

Watson, D. (2007). The future for lifelong learning. Adults Learning, 19(3), 21-23. 
World Bank. (2003). Lifelong learning in the global knowledge economy: Challenges for developing countries. Washington, D.C.: The World Bank. Retrieved from http://siteresources.worldbank.org/INTLL/Resources/Lifelong-Learning-in-theGlobalKnowledge-Economy/lifelonglearning_GKE.pdf

Xihe Zhu \& Senlin Chen. (2017). Effects of cognitive demand on situational interest and running task performances. Educational Psychology, 37(7), 907-920.

Yusop, M. M., \& Abbas, L. N. (2016). Kesediaan guru teknikal melanjutkan pengajian ke peringkat tinggi. Online Journal for TVET Practioners, 1(1). 1-13. 